\title{
USING GIS AND EARTHQUAKE SCENARIOS FOR THE ASSESSMENT OF EMERGENCY RESPONSE IN CASE OF A STRONG EARTHQUAKE. AN APPLICATION IN THE URBAN AREA OF THESSALONIKI, GREECE
}

\author{
Stratou M. ${ }^{1}$, Savvaidis A. ${ }^{2}$, Papadopoulou M. ${ }^{3}$, and Panagiotopoulos D.G ${ }^{4}$ \\ ${ }^{1}$ Rural and Surveying Engineer, MSc A.U.Th., mstratou@topo.auth.gr \\ ${ }^{2}$ Institute of Engineering Seismology \& Earthquake Engineering (ITSAK), PhD A.U.Th., Georgikis \\ Scholis 46, P.O. Box 53 GR-5510 Finikas, Thessaloniki Greece, alekos@itsak.gr \\ ${ }^{3}$ Department of Cadastre, Photogrammetry and Cartography, School of Rural and Surveying En- \\ gineering, Aristotle University of Thessaloniki, 54124, Thessaloniki, Greece, papmar@topo.auth.gr \\ ${ }^{4}$ Department of Geophysics, School of Geology, Aristotle University of Thessaloniki, 54124, \\ Thessaloniki, Greece, panagiot@geo.auth.gr
}

\begin{abstract}
The aim of this paper, which is part of the M.Sc Thesis of the first author, is an initial attempt for the assessment of the emergency response through the road network of the Urban Area of Thessaloniki (UAT) after a strong earthquake. The areas of the road network that are to become inaccessible either due to partial collapse of buildings or due to destruction of the road axes by rupture zones, are detected. The inaccessible parts are determined for the cases of three earthquake scenarios using the values of the Peak Ground Acceleration (PGA), which were calculated for about 6000 points over the UAT, as well as spatial overlay tools of a GIS. In the end, by applying network analysis and according to the situation of the network after the earthquake, the possibility of movement of the fire engines and ambulances was studied and least cost routes from ambulance stations to UAT hospitals were tracked.
\end{abstract}

\section{INTRODUCTION}

Nowadays, the use of GIS, mainly by state agencies, has a worldwide application, in order hypothetical natural disasters (fires, floods, earthquakes etc.) scenarios to be materialized and the corresponding emergency response to be programmed (Coppock 1995, Johnson \& Nelson 2000).

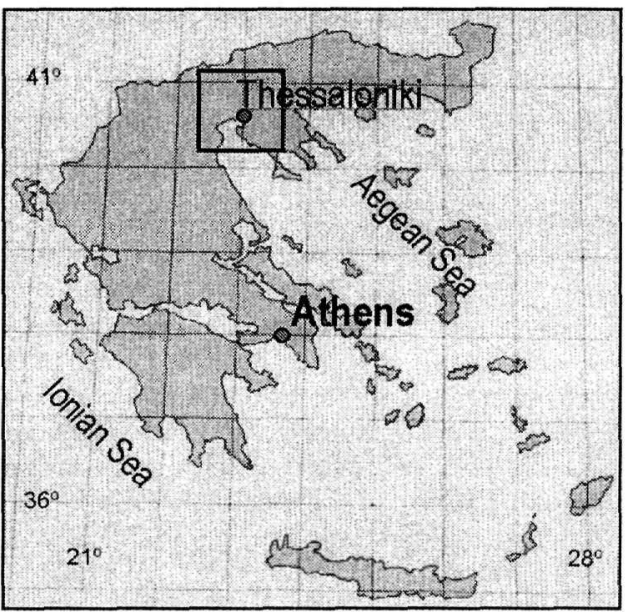

Figure1. The site of the study area
In case of earthquakes, the development of strategies for the reduction of the earthquake consequences is extremely interesting, especially for states that belong to areas of intense seismicity. For this reason, various significant studies based on earthquake scenarios and GIS utilities have taken place internationally (Gittings \&Towers 1995, Birkin et al. 1996, de Polo et al. 1997, ESRI 2000, Johnson 2001, Ozge 2002, Basoz et al. 2003, USGS 2003).

It is particularly significant, a city to be ready in advance for the encounter of difficult conditions that will probably occur in case of a strong earthquake. Being prepared, the city authorities will be able to reduce cost in human lives and damages.

In this paper, an attempt was made in order the accessibility of the road network of the UAT (Fig.1) after a strong earthquake to be approxi- 
mately given and the possibility of movement of the fire engines and ambulances to be studied.

Three possible earthquake scenarios that can very seriously affect the UAT were chosen. The geotechnical and seismological characteristics of the study area were taken under consideration and the Peak Ground Acceleration (PGA) for about 6000 points over the UAT was calculated. It was assumed that in a certain area the buildings might partially collapse (masonry, balconies etc.) if PGA exceeds a particular value. Using the spatial overlay tools of a GIS for each scenario, the parts of the road network that become inaccessible, either due to partial collapse or due to destruction of the road axes by rupture zones, were detected. After that, using network analysis, the fire stations' allocation as well as least cost routes from ambulance stations to UAT hospitals were tracked. Geometry and accessibility were used as descriptive characteristics of the road network, while no traffic or construction information was used.

For the accomplishment of this paper the following software packages were used:

-AutoCAD2000 by Autodesk for the creation of digital spatial layers of the GIS

- Istos 2000 for AutoCAD by Polyhedron Inc. for coordinate transformations

-ArcGIS 8.1 by ESRI for spatial overlay procedures, the creation of derivative digital layers and the drawing of final maps.

-ArcINFO 7.2 by ESRI, for network analysis procedures.

\section{SPATIAL OVERLAY AND NETWORK ANALYSIS}

Spatial analysis is applied on the digital layers of the spatial database of a GIS. It is the procedure that is used for the comparison of the positions of spatial cartographic objects that belong to the same layer or to different layers and the determination of the spatial and/or statistical relation between them. This comparison in accordance to the descriptive properties of the objects gives answers to various queries that are put to the GIS (ESRI 1994a, Laurini \& Thomson 1994).

In this paper two significant groups of spatial analysis tools were used: spatial overlay and network analysis.

The spatial overlay procedures use the rules of Boolean algebra for the combination of objects that belong to different layers and gives answers to queries that have to do with points (point in polygon queries), lines (line in polygon, line on line queries) or areas (polygon on polygon or region queries) (ESRI 1994a). A common cartographic coordinate system for all layers of the spatial database is required as well as the determination of topology between the objects on each layer (point, line or polygon topology) (Laurini \& Thompson 1994).

Network analysis uses the descriptive information and the geometry of a network for the study of alternative paths, tours, allocation, tracing, location-allocation of activities etc. (ESRI 1994b).

A network is a system of line elements connected in junctions. These junctions are called nodes and the line element that connects two nodes is called a link. Each link is represented by a pair of nodes. The first node (from-node) is the beginning of the link and the second node (to-node) is the end of it.

The descriptive characteristic of a link is the cost that is required for travelling along it. On the other hand, nodes can have various properties according to the kind of analysis taking place on the network (they can be allocation centres, stops in a tour, position with specific traffic characteristics etc.).

Finding a shortest or least cost path between two nodes is one of the most popular procedures of network analysis. A GIS can answer the question:" which is the shortest or less expensive or less time consuming path between position A and position B on the network?" The problem can become more complicated by adding factors like traffic control, inaccessibility of certain network areas due to damages etc.

Allocation is the modeling of supply and demand in a network. Supply refers to the quantity of resources a centre (node) has available for utilization through the network. Demand quantifies the requirement for resources from other points on the network. A significant descriptive characteristic of the center is the maximum impedance that is a limit to the allocation of the existing supply without regard to the demand. During the allocation process the supply, demand and maximum impedance are combined and the catchment area of each centre is determined. 


\section{CREATION OF DIGITAL INFORMATION LAYERS}

The function of the GIS in use depended on original as well as derivative information layers. The original layers were created by digitization of existing analogical maps while the derivative layers were formed by the GIS software. The derivative layers were used in the calculation of the PGA values as well as in the effectuation of the earthquake scenarios.

The six original layers that came from cartographic, seismological and geotechnical data are:
A. The road network over the UAT (lines) (Fig.2)
B. Positions of UAT fire stations (points) (Fig.2)
C. Positions of UAT ambulance stations (points) (Fig.2)
D. Positions of UAT hospitals (points) (Fig.2)
E. Ground formations over the UAT (polygons) (Fig.3)
F. Faults that neighbour on the UAT (lines) (Fig.4)
The three derivative layers are:
G. A grid of a $100 \mathrm{~m}$ step (Stratou 2003) that covers all the UAT area with about 6000 nodes. For the entire grid nodes the PGA values were calculated (points).
$\mathrm{H}$. Areas of a certain value of PGA that were compiled through the grid mentioned above (polygons) (Fig. 5)
I. Buffer zones around certain faults (polygons)

The common cartographic coordinate system used for all layers was UTM (Hayford ellipsoid, zone 34, ED50) (Fotiou \& Livieratos 2000). In this system the simultaneous cartographic depiction and elaboration of data over the UAT (layers A-E, G-I) and of data of a much greater geographic area (layer F) was served (Stratou 2003).

\subsection{Original digital layers}

\subsubsection{The road network layer}

The creation of the road network layer is an important part of data elaboration as far as the cartographic database is concerned, because it comprises data of various sources, scales, cartographic systems etc.

The final layer came from the cartographic combination of the following:

1. Digitized road axes that came from the digital map of building blocks (Koupadi \& Papadopoulos 1996) (1:5000, Hatt projection) for ten municipalities of the UAT (Municipality of Agios Pavlos, Efkarpia, Evosmos, Kalamaria, Kordelio, Menemeni, Sikies, Triandria and a part of the Municipality of Thessaloniki)

2. Digitized road axes of the extension of the municipality of Evosmos, the Kifisia extension of the municipality of Thessaloniki, the axes of the municipality of Pilea, the ring road of the UAT and part of the national road to Athens that connects the UAT with the area of Sindos (Fig.2). The initial cartographic material (Denco et al. 2000) for all the above road parts comprised analogical maps at 1:5000 and of unknown cartographic projection. The digitized data were transformed into the Hatt projection through the classic procedure of recognition of control points on other existing maps of the area in known projection (Arvanitis et al. 1990).

3. Digital maps of road axes for the municipalities of Stavroupolis, Neapolis and Polichni at 1:5000 and in Hatt projection (Kanelleas et al. 1996, Gioldelis and Spyrou 1997, Kaldoglou and Kalogeropoulos 1997)

The total road network layer was accomplished through the union of the above three categories of data. The transformation of all the Hatt coordinates into UTM coordinates followed. The length of each link as well as its impedance that is its accessibility in every scenario comprised their descriptive information.

\subsubsection{The layers of the emergency response stations and hospitals}

In the network analysis performed in this paper the positions of the hospitals as well as the fire and ambulance stations were identified with network nodes. Three different point levels (each for every kind of service) were created (Fig.2). 


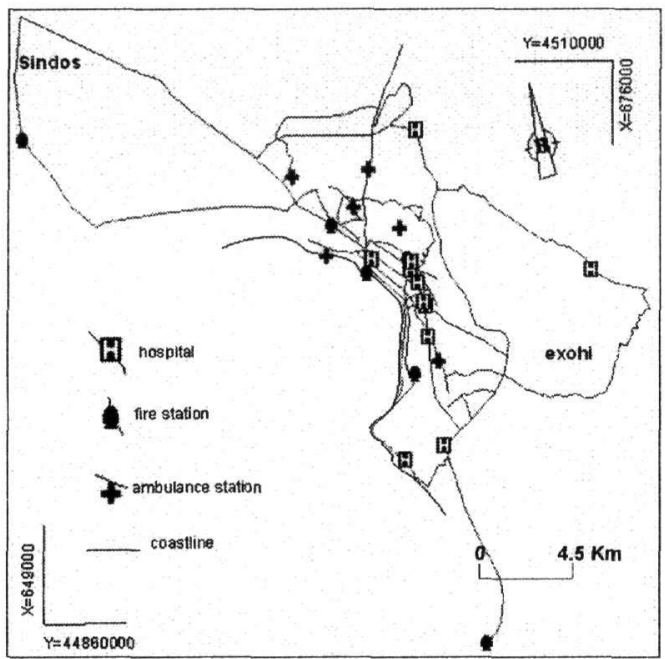

Figure 2. High roads, the limits of the road network and the positions of hospitals, fire and ambulance stations on the UAT are depicted.

\subsubsection{The layer of the ground formations} According to Anastasiadis et al. (2001), the UAT belongs to the geotechnical Zone of Axios River. This zone is tangential to the Serbomacedonia Zone that is one of the most active seismotectonic areas in Europe. The digital layer of the ground formations was created by digitization of the analog geotechnical map of Anastasiadis et al. (2001), given at a scale of 1:100,000 and in Hatt projection. The Hatt coordinates were transformed into UTM coordinates. In figure 3 the geotechnical map that divides the study area into formation zones is depicted. In each zone the corresponding formation, thickness and their volumetric distribution from the lower to the higher level on the surface is known. This layer has a polygon topology. The descriptive characteristics for each polygon are the category of the ground formation and the thickness of the higher layer.

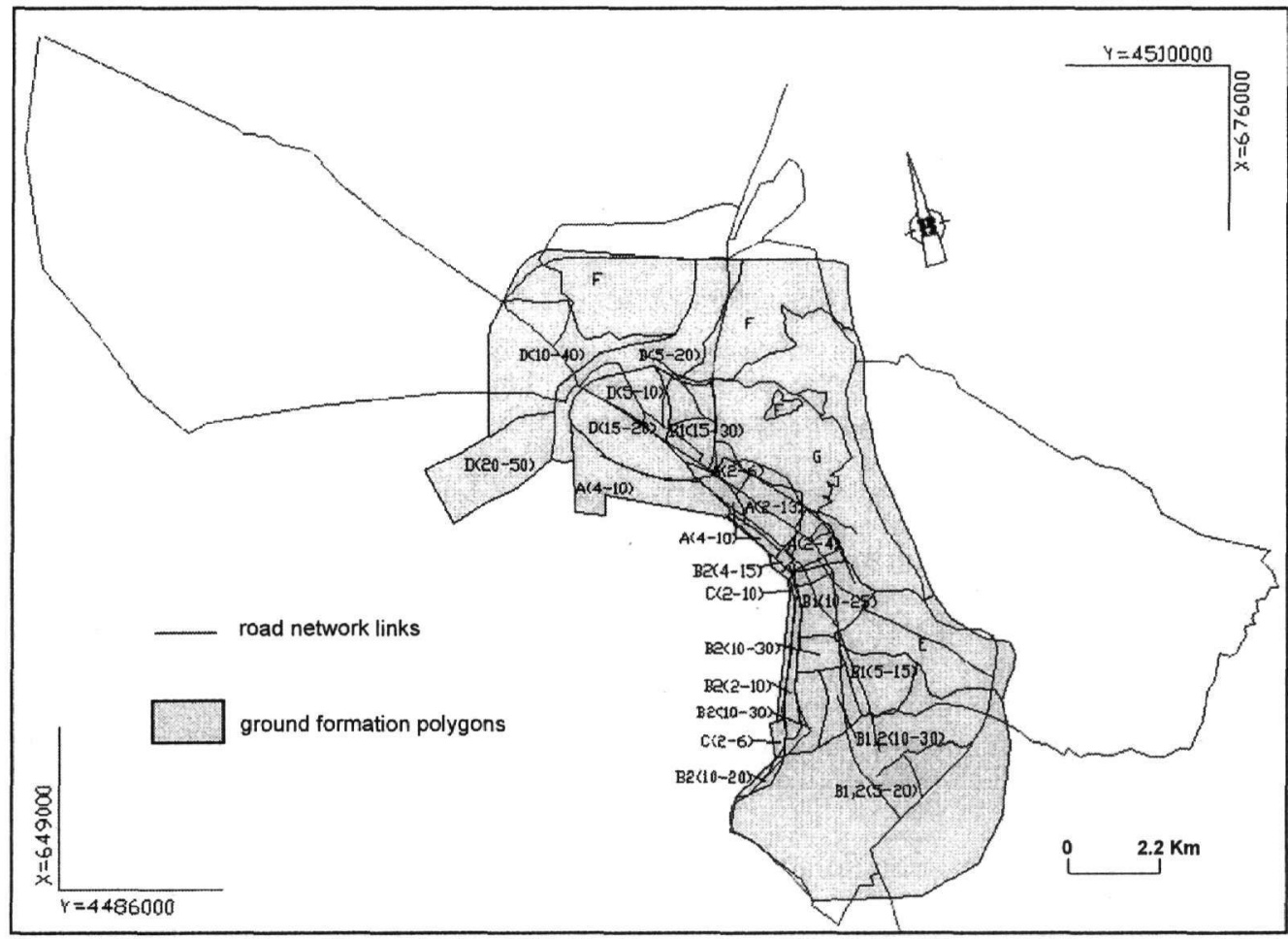

Figure 3. The ground formations under the UAT. The high roads and the limits of the road network are depicted. For each ground formation its category as well as the thickness (in meters) of its higher layer is given in parenthesis inside the corresponding polygon on the map (Anastasiadis et al. 2001).

\subsubsection{The layer of the faults}

The three faults used in this paper were chosen from a wider group of twelve faults (Fig. 4) that are situated in Macedonia, Greece and in Bulgaria. This wider group was used because it 


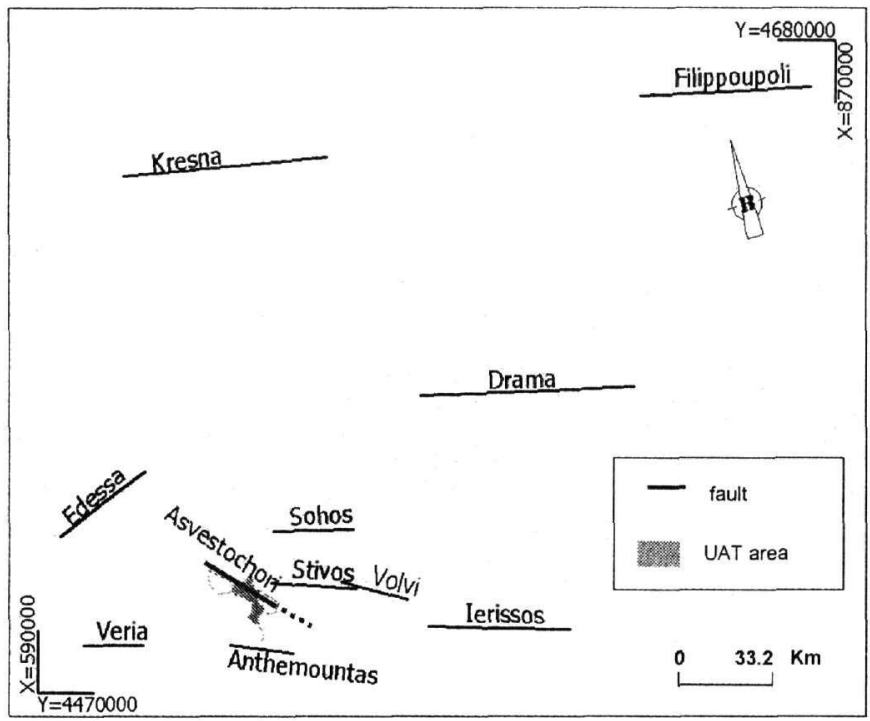

Figure 4. The twelve faults are depicted in relevance to UAT. Asvestochori 1 is the dotted line while the Asvestochori2 is the remaining black continuous line of the Asvestochori fault. Two of the faults (Kresna and Fillipoupoli) belong to Boulgaria while the others belong to Macedonia, Greece. comprises faults that caused strong earthquakes in the past. According to historical evidence, all those earthquakes had significant consequences on the UAT (Papazachos et al. 2001). The Asvestochori fault is divided into two parts: Asvestochori1 and Asvestochori2 (Fig. 4). The two parts of the Asvestochori fault have not caused any disastrous earthquake yet, but they are considered very important on a serious consequence point of view (Mountrakis et al. 1997). Accordingly to that, the Asvestochori faults become particularly interesting for the creation of an earthquake scenario.

For each one fault the geodetic coordinates $\varphi$ and $\lambda$ (Hayford ellipsoid, ED50) of their beginning, end and middle point were known. The geodetic coordinates were transformed into

UTM coordinates and through the GIS software in use, a layer of line topology was created.

The UTM system was selected as the uniform system of all the cartographic layers in order the two Bulgarian faults to be included in the data elaboration.

\section{ELABORATION OF GEOLOGICAL DATA AND COMPILATION OF EARTHQUAKE SCENARIOS}

The Peak Ground Acceleration (PGA) is a parameter of a strong ground motion. It is essential for the determination of the inaccessible parts of the UAT road network due to possible partial collapse of buildings' masonry, balconies etc. in areas where the PGA value exceeds a certain limit. The PGA at a given ground point is a function of the magnitude of the earthquake, the distance of the point from the fault that caused the earthquake and the type of ground formation where the point lies. The PGA value in this paper was calculated according to the following formula (1) (Margaris et al. 2001):

$\operatorname{InPGA}=3.52+0.70^{*} \mathrm{M}_{w}-1.14^{*} \ln \left(\mathrm{R}^{2}+7^{2}\right)^{1 / 2}+0.12^{*} \mathrm{~S} \pm 0.70$

where $M_{w}$ is the moment magnitude, $R$ is the epicentral distance, and $S$ is the type of the corresponding ground formation according to NEHRP (Margaris et al. 2001)

In this paper, for the exploitation of the PGA, a grid of about 6000 points with known ground formations was created over the area the UAT. The grid step was $100 \mathrm{~m}$, so that all the ground formations even those that cover small areas to correspond with grid points.

Using spatial overlay (point-in-polygon) between the layer of the grid points and the layer of the ground polygons, the corresponding formation for each point was determined. The results of this point-in-polygon procedure were saved as descriptive information for all the grid points.

Next, the distance between each fault under study and each grid point was calculated. The earthquake is likely to come from any point of a fault. For this reason, the distance between a grid point and the middle point of the fault as well as the distance between a grid point and the nearest to the UAT point of the fault were calculated. For the faults of Asvestochori1, Asvestochori2, An- 
themountas, Drama, Fillippoupoli, lerissos, Kresna, Sohos, Stivos and Volvi, the central point and the west end were used while for the faults of Edessa and Veria the central point and the east end were used.

According to past earthquakes from the twelve faults, the $M_{w}$ that will be probably caused by each fault was determined (Papazachos and Papazachou 2003).

For the chosen points of all the faults in concern, the maximum, the minimum and the mean value of PGA were calculated as well as the difference between the maximum and the minimum value. According to the values above the epicentres that were chosen to be further studied were:

1. The west end of the Stivos fault

2. The west end of the Sohos fault

3. The central point of the Asvestochori2 fault

The collapse of masonry, balconies etc. depends on the maximum value of PGA. For the earthquake from the Sohos fault it is assumed that there will be damages in UAT areas where PGA $\geq 110$ $\mathrm{cm} / \mathrm{sec}^{2}$. The above PGA value corresponds with a macroseismic intensity of $\mathrm{VI}$ at the Modified

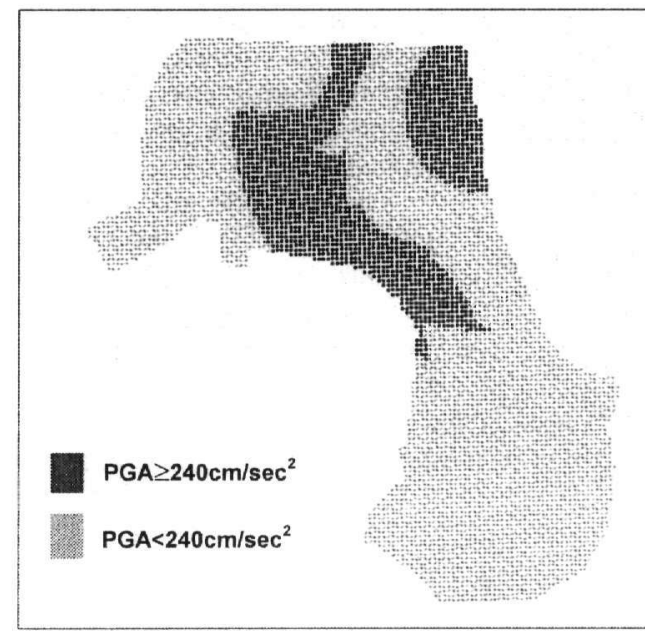

Figure 5. Limit values of PGA over the UAT, defined for scenario 3 of the Asvestochori2 fault.

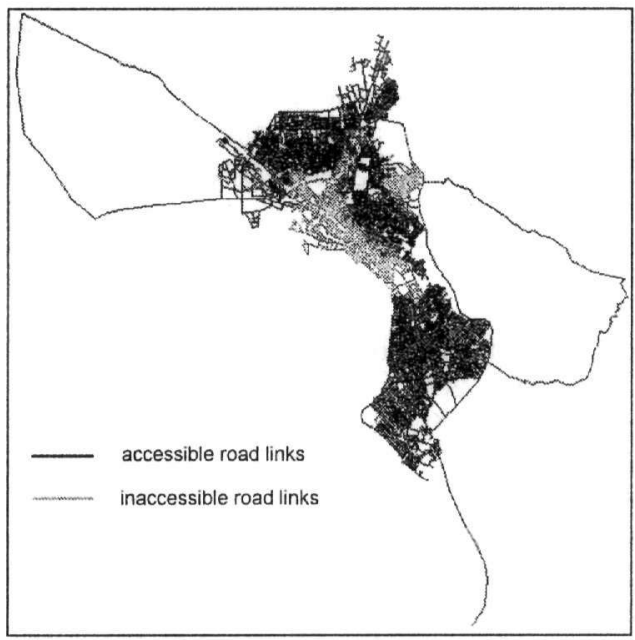

Figure 6 . The inaccessible road links for case 1 of scenario 3 , are depicted in gray colour.
Mercalli (MM) scale. For the earthquakes from the Asvestochori2 and Stivos faults it was assumed that there will be damages in UAT areas where $P G A \geq 240 \mathrm{~cm} / \mathrm{sec}^{2}$ a value that corresponds to intensity $\mathrm{VII}$ at the MM scale (Koliopoulos et al. 1998). In figure 5 the limit values of PGA for the Asvestochori2 fault are indicatively depicted. It is pinpointed that despite the fact that the intensity at MM does not correspond with partial damages of buildings, the chosen PGA limit values can cause collapse of masonry, balconies etc. since the UAT buildings are old and no information about their vulnerability is known. Data about the buildings' vulnerability would be extremely useful for the determination of the damages and the calculation of the corresponding PGA values, but the whole procedure is beyond the scope of this study.

The three earthquake scenarios formatted for the chosen faults, epicentres and PGA values are:

Scenario 1: The earthquake comes from the west end of the Stivos fault and has a macroseismic intensity of VII at the MM scale. It is assumed that there will be partial collapse in the UAT areas where $P G A \geq 240 \mathrm{~cm} / \mathrm{sec}^{2}$.

The accessible by rescue vehicles links of the road network were located through the following procedure: the grid points with known PGA values were divided into two groups, one that comprised the points with $P G A \geq 240 \mathrm{~cm} / \mathrm{sec}^{2}$ and a second that comprised the points with $P G A<240$ $\mathrm{cm} / \mathrm{sec}^{2}$ (similar to Fig. 5). Through these two categories, a polygon layer came from the classified grid points. The descriptive information of these new polygons was a code indicating PGA over or under the limit of $240 \mathrm{~cm} / \mathrm{sec}^{2}$. With a spatial overlay between the layer of the road network and the layer of the PGA polygons (line-in-poly- 
gon) the links that correspond to polygons of $P G A \geq 240 \mathrm{~cm} / \mathrm{sec}^{2}$ (the inaccessible links) were localized.

Scenario 2: The earthquake comes from the west end of the Sohos fault and has a macroseismic intensity of $\mathrm{VI}$ at the MM scale. It is assumed that there will be partial collapse in the UAT areas where $P G A \geq 110 \mathrm{~cm} / \mathrm{sec}^{2}$. The accessibility of the road links was determined through the GIS procedure described above.

Scenario 3: The earthquake comes from the central point of the Asvestochori2 fault and has a ma-

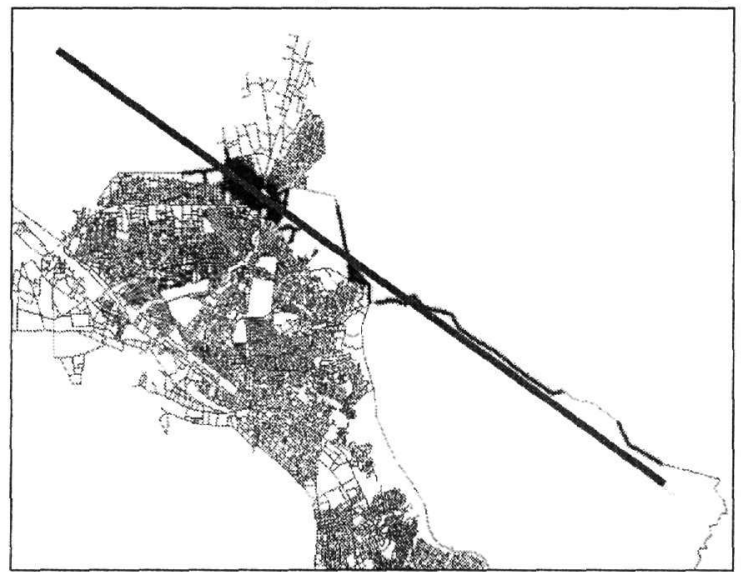

Figure 7 . The extra (to those depicted in Fig. 5) inaccessible road links due to destruction of the road axes by rupture zone of Asvestochori2 (thick black line) are depicted in black colour (scenario 3, case 3 ). croseismic intensity of VII at the MM scale. It is assumed that there will be collapse of masonry and balconies in the UAT areas where $P G A \geq 240 \mathrm{~cm} / \mathrm{sec}^{2}$. This scenario comprised three different cases.

Case 1: Partial collapse for the UAT areas with $P G A \geq 240 \mathrm{~cm} / \mathrm{sec}^{2}$. The inaccessible links were localized through the GIS procedure described in scenario 1 (Fig. 6).

Case 2: Partial collapse for the UAT areas with $P G A \geq 240 \mathrm{~cm} / \mathrm{sec}^{2}$ and destruction of the road axes that are either intersected by the fault or belong to a rupture zone of $300 \mathrm{~m}$ around it. The inaccessible parts of the road network were determined through the PGA polygons as already described. In this case some extra inaccessible parts are localized. Firstly, with a line-on-line procedure between the layers of the faults and the road network, the road links intersected by the Asvestochori2 fault were located. Secondly, a derivative layer of a $300 \mathrm{~m}$ buffer zone around the fault was created. The road parts that belong to this zone were determined through a line-in-polygon overlay between the layer of the road network and the layer of the buffer polygon.

Case 3: This case is the same with case 2. The only difference is that all the road links that belong to the ring road, due to their special construction standards, are considered intact, despite the fact that they are intersected by the Asvestochori2 fault and belong to the $300 \mathrm{~m}$ rupture zone (Fig. 7). The procedures for the determination of the inaccessible parts are the ones described for case 2. Additively, the ring road links are excluded from the set of inaccessible parts.

Case 4: This case is also like case 2. The difference is that all the road links that are intersected by the fault or belong to the part of the $300 \mathrm{~m}$ buffer zone that lies to the south of the fault (footwall block) are considered inaccessible, while the parts that belong to the rest of the zone are accessible. The procedures for the determination of the inaccessible parts are the ones described for case 2. In this case the rupture zone and the corresponding derivative polygon layer is smaller in area.

\section{NETWORK ANALYSIS ACCORDING TO SCENARIO 3 (CASE 4)}

There were a considerable number of results after the application of network analysis on the conditions configured by each of the scenarios. In this paper, some results of the network analysis performed under the conditions of scenario 3, case 4, are indicatively presented, since the certain scenario and case make a particularly interesting combination for the study area.

The speed of all rescue vehicles was assumed to be $70 \mathrm{~km} / \mathrm{h}$ for all the faces of analysis.

Using the network tools, the allocation of each fire and each ambulance station for a maximum impedance of 15 min was located and the parts of the UAT served by each station within this time were determined. The allocation procedure was performed for the road network under normal conditions (Fig.8a) as well as under the conditions of the selected scenario and case (Fig.8b). According to this analysis three of the six fire stations, two of the ten ambulance stations and six of the eleven hospitals cannot serve the UAT after the earthquake because they are situated in the central 
part of the study area where the most inaccessible road links lie (Stratou 2003), (Fig. 2, Fig. 6, Fig.7).

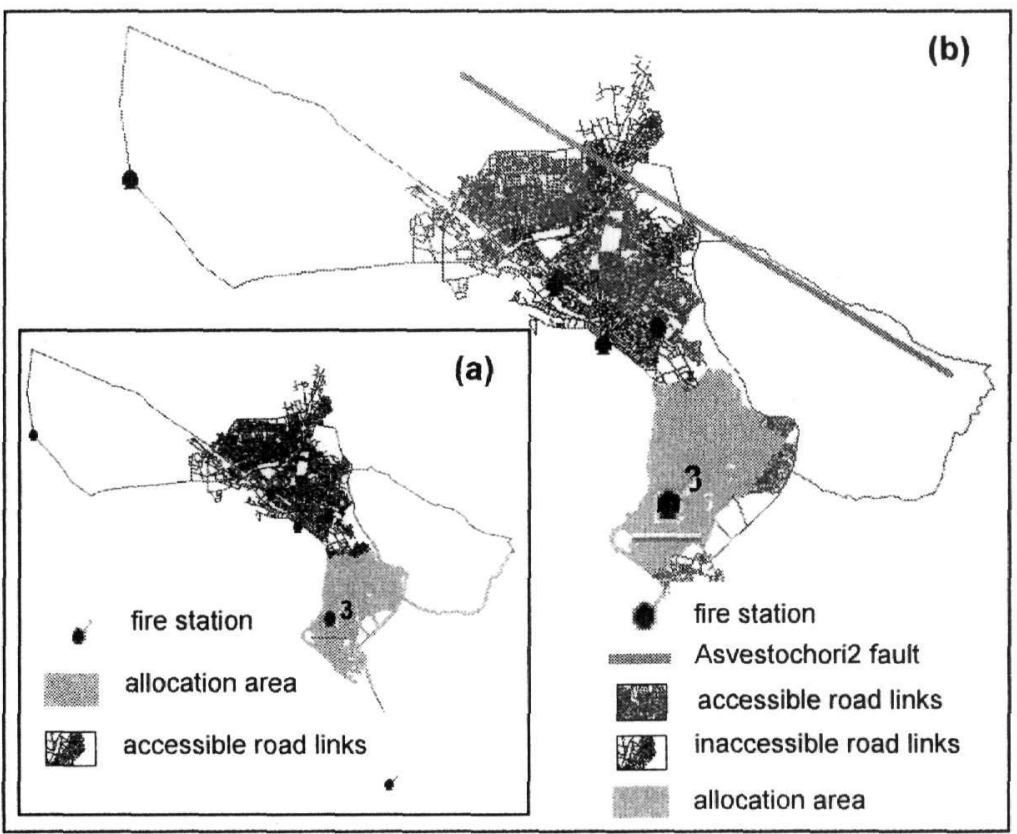

Figure 8: (a) Allocation of the $3^{\text {rd }}$ fire station under normal conditions. (b) Allocation of the $3^{\text {rd }}$ fire station after the strong earthquake from the Asvestochori2 fault (scenario 3 , case 4).

A great number of routes between an ambulance station and a hospital through a randomly selected node, which was assumed as the position of an incident, were analyzed and shortest paths were tracked (Stratou 2003), (Fig 9a, Fig. 9b). Due to the fact that most of the hospitals are gathered in the inaccessible area of the UAT, the GIS software was unable to track a path for several of the station-hospital combinations.
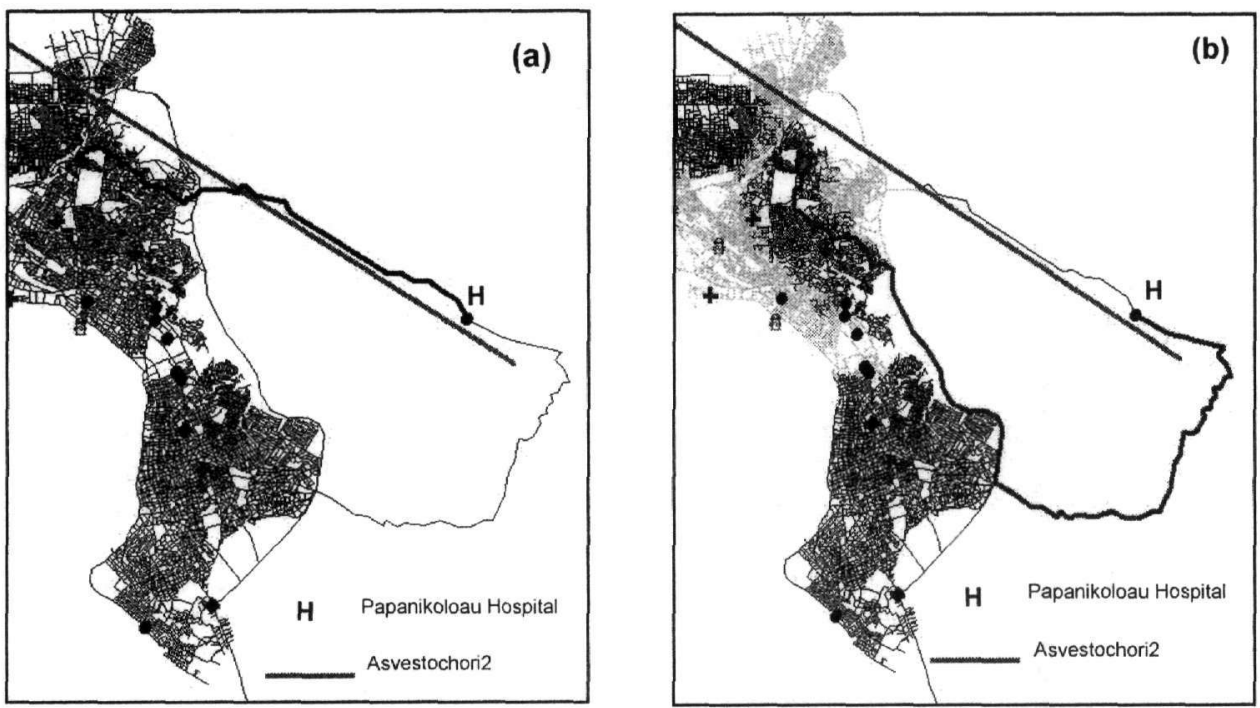

Figure 9. (a) A least cost path (in thick black line) tracked between an ambulance station in the centre of the UAT and Papanikolaou hospital, under normal conditions. The tracked shortest path is $11 \mathrm{~km}$ and the travel time is 9 min. (b) A least cost path (in thick black line) tracked between the same ambulance and Papanikolaou hospital after the strong earthquake of scenario 3, case 4 . The gray area of the UAT comprises the inaccessible parts of the road network. The tracked shortest path is $24 \mathrm{~km}$ and the travel time is $21 \mathrm{~min}$. 
The consequences of strong earthquakes on the urban areas of organized societies are severe. Their intensity through time and space depends on many factors that are directly connected with the appearance of this phenomenon (the distance of the epicentre, the magnitude of the earthquake, parameters of propagation of the released energy, raypaths of the propagation, geological infrastructure and soil foundation etc.) as well as the degree of the organization of the societies, the level of crisis management, the level of technology and its development rate in the recent past. According to the above, the timely and proper encounter of these consequences is a branchful subject. The knowing of geosciences and especially of Seismology consists a significant infrastructure for the development of other response technologies also, as far as the prevention and the management of the critical situation are concerned.

The use of the GIS tool by state agencies for all natural disasters and earthquakes in particular, has been proved to be necessary worldwide (Coppock 1995, Gittings \&Towers 1995, Birkin et al. 1996, de Polo et al. 1997, ESRI 2000, Johnson \& Nelson 2000, Johnson 2001, Ozge 2002, Basoz et al. 2003, USGS 2003). Nevertheless, the success of any enterprise depends on the data flow in real time for most of the problem's parameters that are connected with the evolution of the phenomenon as well as with the condition of the urban area under consideration.

In this paper, which is an initial attempt towards the assessment of the emergency response after a strong earthquake, three scenarios of earthquakes from three active seismic faults near the UAT (faults of Stivos, Sohos and Asvestochori) were implemented. For all the scenarios, the PGA that is an important parameter of a strong earthquake motion was exploited for the detection of the UAT areas that will probably face serious problems due to partial collapse. In addition to this, by applying spatial overlay of the digital layers of cartographic information the destructed by the faults or the rupture zone road links are localized. Thereafter, using the network analysis tools, the emergency response in the various sectors of the UAT was assessed in an approximative point of view.

During this study the necessity for seismological, geotechnical and chartographical data of less uncertainty was proved to be very important as well as the existence of traffic data or data concerning the buildings' vulnerability, the availability of using rescue units during the crisis etc. It was also pinpointed the usefulness of a GIS as a tool of crisis management (when Xenokratis plan is activated) and as a tool for decision making in cases like finding proper locations for rescue stations or rearranging the sites of them.

\section{AGKNOWLEDGMENTS}

The authors would like to thank two ITSAK members: Dr. A. Anastasiadis for his courtesy to give them access to the geotechnical data for the UAT and Dr. V. Margaris for a very helpful discussion on the subject. They would also like to express their sincere appreciation to the two anonymus reviewers for their useful comments and critical reviews of the manuscript.

\section{REFERENCES}

Anastasiadis A., Raptakis D. \& Pitilakis K. 2001. Thessaloniki's Detailed Micro zoning: Subsurface Structure as Basis for Site Response analysis, Pure and Applied Geophysics, vol. 158, 2597-2633

Arvanitis, A., Karnavou, E., Maniatis, I., Miridis, M., Papadopoulou, M., \& Paraschakis, I. 1990. The Creation of a Derived Geometrical Base for Thematic Maps, Technical Chronicles, vol. 11, no 3, 117-132 (in Greek with English extended summary)

Basoz, N., Williams, M., \& Kiremidjian, A. 2003. A GIS-Based Emergency Response System for Transportation Networks, in Beavers J., (ed). 2003. Advancing Mitigation Technologies and Disaster Response for Lifeline Systems, 926-935

Birkin, M., Clarke, G., Clarke, M., Wilson, A. 1996. Intelligent GIS-Location Decisions and Strategic Planning, Geoinformation International, $31-37$

Coppock, T. 1995. GIS and Natural Hazards: An Overview from a GIS Perspective, in Carrara A. \& Guzzeti F. (eds), Geographical Information Systems in Assessing Natural Hazards, 22-24

de Polo, G., Anderson, J., de Polo, D., Price, J. 1997. Earthquake Occurrence in the Reno-Carson City Urban Corridor, Seismological Research Letters, vol. 68, May/June, 1997, 401-412 
Denco Consultants Engineers Ltd., TRADEMCO - Efmolpidis B. - Emmanoulopoulos G., Agelidis I. \& Company, (TRUTh S.A.), Macedonian E.T.M.E.E.-INFODHM G.P., WS ATKINS Ltd, STEER DAVIES GLEAVE, 2000. General Study of Transportation and Traffic in the Urban Area and Greater Area of Thessaloniki Face B, 2000.

ESRI, 1994a. Understanding GIS. The ArcInfo Method, ESRI, (Performing Geographic Analysis) 53pp..

ESRI 1994b. Network Analysis, ESRI, 266pp.

ESRI, 2000. Earth-Shaking Science, ArcUser, January-March, 26-27

Fotiou, A., \& Livieratos, E. 2000. Geometrical Geodesy and Networks, Thessaloniki, Ziti Publication, 440pp. (in Greek)

Gioldelis, D., \& Spirou, A. 1997. Address Geocoding of Trade Activities in the Greater Urban Area of Thessaloniki, Greece, Diploma Thesis, Department of Cadastre, Photogrammetry and Cartography, Aristotle University of Thessaloniki, 75pp. (in Greek).

Gittings, B. \& Towers, A. 1995. Earthquakes and GIS on the Information Superhighway, GIS World, August, 6871

Johnson, R., \& Nelson, L. 2000. Risk Analysis and Response - GIS and Public Safety, ArcUser, JanuaryMarch, 12-14

Johnson, R. 2001. GIS Aids Emergency Response, ArcUser, July-September 2001, http://www.esri.com/news/ arcuser/0701/umbrella15.html

Kadogiou, S., \& Kalogeropoulos, F. 1997. Address Geocoding of Trade Activities in the Municipality of ThessaIoniki, Greece, Diploma Thesis, Department of Cadastre, Photogrammetry and Cartography, Aristotle University of Thessaloniki, 60pp. (in Greek)

Kanelleas, P., Kontogianni, E., \& Kotta, B. 1996. Address Geocoding of Trade Activities in the Municipalities of Ampelokipi, Neapolis, Stavroupolis and Polichni, Greece, Diploma Thesis, Department of Cadastre, Photogrammetry and Cartography, Aristotle University of Thessaloniki, 80pp. (in Greek)

Koliopoulos, P., Margaris, B. \& Klimis, N. 1998. Duration and Energy Characteristics of Greek Strong Motion Records", Journal of Earthquake Engineering, vol. 2, no. 3, 1998, 391-417

Koupadi, E., \& Papadopoulos, N. 1996. Organization of Demographic Characteristics (1991) in the Greater Urban Area of Thessaloniki in a GIS Environment, Diploma Thesis, Department of Cadastre, Photogrammetry and Cartography, Aristotle University of Thessaloniki, 60pp. (in Greek)

Laurini, R., \& Thomson, D. 1994. Fundamentals of Spatial Information Systems, Academic Press, 680pp.

Margaris, B., Papazachos, C., Papaioannou, Ch., Theodulidis, N., Kalogeras, I., \& Skarlatoudis, A. 2001. Empirical attenuation relations for the horizontal strong ground motion parameters of shallow earthquakes in Greece, Proc. $2^{0}$ Hellenic Conference on Earthquake Engineering and Engineering Seismology, Thessaloniki 2001, September 28-30, Greece, 1, 27-36.

Mountrakis, D., Kilias, A., Pavlides, S., Sotiriadis, L., Psilovikos, A., Astaras, Th., Vavliakis, E., Koufos, G., Dimopoulos, G., Soulios, G., Christaras, V., Skordilis, M., Tranos, M., Spiropoulos, N., Patras, D., Syrides, G., Lambrinos, N. \& Laggalis, Th. 1997. Neotectonic map of Greece, Sheet of Thessaloniki, Special Publication of OASP (Earthquake Planning and Protection Organization) of Greece.

Ozge, Y. 2002. Urban Information Systems for Earthquake-Resistant Cities: A Case Study on Pendik, Istanbul, MSc, Department of Geodetic and Geographic Information Technologies, The Graduate School of Natural and Applied Sciences of the Middle East Technical University, http://www.metu.edu.tr/home/wwwggit/eng/studies/ggit/past_studies.htm

Papazachos, B.C. \& Papazachou, C. 2003. The earthquakes of Greece, Ziti Publication, 286pp. (in Greek)

Papazachos, B.C., Mountrakis, D., Papazachos, C.B., Tranos, M., Karakaisis, G.F. \& Savvaidis, A. 2001. The faults which have caused the known major earthquakes in Greece and surrounding region between the $5^{\text {th }}$ century $\mathrm{BC}$ and today, Proc. $2^{0}$ Hellenic Conference on Earthquake Engineering and Engineering Seismology, Thessaloniki 2001, September 28-30, Greece, 1, 17-26. (in Greek)

StRATOU, M. 2003. Using GIS and Earthquake Scenarios for the Assessment of Emergency Response in Case of a Strong Earthquake. An Application in the Urban Area of Thessaloniki, Greece, MSc Thesis, Department of Cadastre, Photogrammetry and Cartography, Aristotle University of Thessaloniki, 183pp. (in Greek).

USGS. 2003. Geographic Information Systems, http://erg.usgs.gov/isb/pubs/gis_poster 